\title{
INDEX TO VOLUME 19
}

\section{A}

A quantitative study of regeneration by inductive feed back................. Aberrations of photographic lenses........... Absorption of radio waves. spectra. See Spectra.

Actinoelectrical properties of molybdenite ... Alternating current resistance and inductance of solenoids. current theory of regeneration.............

Alloy, iron-carbon, determination of critical ranges by thermoelectric means............

Alloys, determination of iridium in........... platinum.......................... preparation of.

Aluminum alloys, thermal expansion........ copper alloys, thermal expansion.......... manganese alloys, thermal expansion..... copper alloys, thermal expansion.....

silicon alloys, thermal expansion.......... copper alloys, thermal expansion..... manganese alloys, thermal expansion....................

thermal expansion.................... zinc alloys, thermal expansion........... Amateur, effect of fading on reception by.... radio wave finding...................

Antenna, airplane, directive receiving prop-

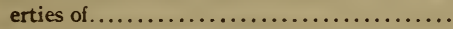
double coil........................ double coil, directional transmission, characteristics of .................... loop, transmitting................... Antimony, spectral classifications, critical potentials, and absorption spectra.......... Applications of the interferometer............ Arc spectrum of molybdenum............... Arsenic, spectral classifications, critical potentials, and absorption spectra........... Atmospheric electricity, relation to radio

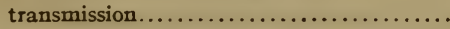
Atmospherics, relation to radio reception....

\section{B}

Barometric conditions, effect on radio transmission................................

Beacon, radio, directive..................

Bennett, A . H., Aberrations of long focus anastigmatic photographic objectives..........

Berliner, J.F. T., Preparation and properties of pure iron alloys: IV. Determination of the critical ranges of pure iron-carbon alloys by the thermoelectric method ...............

Bismuth, spectral classifications, critical potentials, and absorption spectra...........

Brinell hardness numerals, table of

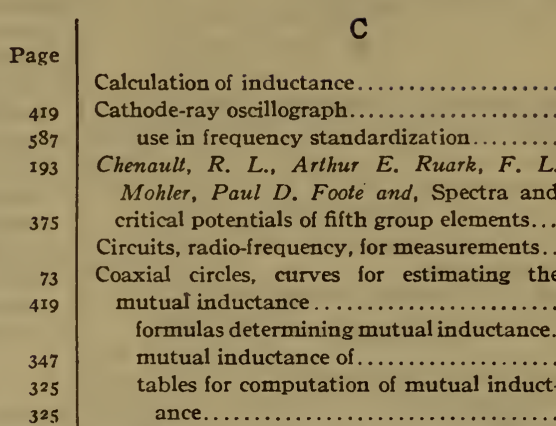
Coblentz, $W W$., Some new thermoelectric and actinoelectric properties of molybdenite - and H. R, Fullon, A radiometric investigation of the germicidal action of ultra-violet radiation ...

- and $C . W$. Hughes, Ultra-violet reflecting power of some metals and sulphides.......

Coil antenna, transmitting.................

Coils, single-layer, alternating-current, resistance and inductance of .................

Ceramics..............................

Critical potentials of arsenic, antimony, and bismuth ranges in iron-carbon alloys, determined by thermoelectric means ....

Crystals ..............................

Curtis, Harvey L., and C. Matilda Sparks, Formulas, tables, and curves for computing the mutual inductance of two coaxial circles 28I - and Robert C. Duncan, A method for the accurate measurement of short-time intervals .................................

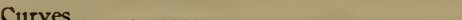

\section{D}

"Dead spots" and radio reception

Decrement ............................. Dellinger, J. H., and J. L. Preston, Methods of measurement of properties of electrical insulating materials.

- L. E. Whitlemore, and S. Kruse, A study of radio signal fading................

Density, electrical insulating materials, measurement.......................

Dielectric constant, insulating materials, measurement........................

Directional variations of radio signals.........

Directive radio transmission............... measurements ......................

Distortion, radio wave..................

Diurnal variations of radio signals...........

Duncan, Robert C., Haney L. Curtis and, A

463 method for the accurate measurement of short-time intervals.

Page

$64 \mathrm{I}$

445

445

463

39

$54 \mathrm{x}$

$54 \mathrm{~T}$

$54 \mathrm{I}$

$54 \mathrm{I}$

375

$64 \mathrm{r}$

577

$28 \mathrm{I}$

73

357

347

307

$54 \mathrm{r}$

17
541

193

$23 \mathrm{I}$

39

I93

39

39

193

$28 \mathrm{I}$

I

28I

193 
Dunmore, F.W., F.H. Engel and, A directive type of radio beacon and its application to navigation.

-, and Francis H. Engel, Directive radio transmission on a wave length of ro meters.

Duralumin, thermal expansion .............. ultra-violet reflecting power.

\section{E}

Electrical properties of insulating materials, measurement.

Einstein

Energy distribution.

Engel, Francis $H .$, Francis W. Dunmore and, Directive radio transmission on a wave length of ro meters.

- and $F . W$. Dunmore, A directive type of radio beacon and its application to navigation.

Expansion, thermal, aluminum molybdenum.......................

Eye, sensibility

\section{F}

Fading, effect on radio reception theory of.

Flash-over voltag ment. Foote, Paul D., Arthur E. Ruark, F. $L$ Mohler, $R$. L. Chenault and, Spectra and critical potentials of fifth group elements..

Formulas..............................

Four-terminal resistors....................

Frequency standardization by means of parallel wires.

Fulton, H.R.,W.W. Coblentz and, A radiometric investigation of the germicidal action of ultra-violet radiation.

\section{G}

Galena, ultra-violet reflecting power......... Gero, W. B., Peter Hidnert and, Thermal expansion of molybdenum.

Generation of very high frequency currents.

Generator for ultra-radio frequency currents

Gibson, K.S., and E.P.T. Tyndall, Visibility of radiant energy.

Gilchrist, Raleigh, Investigations on the platinum metals: IV. Determination of iridium in platinum alloys by the method of fusion with lead.

Glasspots, thermal expansivities of . . . . . . Gold, effect on determination of iridium.....

Gravitation............................ Graphite, ultra-violet reflecting power.......

\section{H}

Hardness, electrical insulating materials, measurement......................... Hartmann test for lenses.................... Hazen, Grace, and Frieda Kenyon, Primary radio-frequency standardization by use of the cathode-ray oscillograph.
Heaviside layer, influence on radio transmission.............................. I93

Heyl, Paul R., Gravitational anisotropy in crystals............................

Hickman, C. N., Alternating-current resistance of single-layer coils..................

Hidnert, Peter, Thermal expansion of aluminum and various important aluminum alloys................................

-, and W. B. Gero, Thermal expansion of molybdenum..........................

High-frequency resistance, measurement.....

Hughes, C. W., W.W. Coblentz and, Ultraviolet reflecting power of some metals and sulphides.............................

Humidity control tank .......................

Hund, August, Theory of determination of ultra-radio frequencies by standing waves on wires.

\section{I}

Impact strength, electrical insulating materials, measurement................... Inductance, alternating current, of solenoids. mutual.

Inductive coupling feed back, study of $\ldots \ldots \ldots \ldots \ldots \ldots \ldots \ldots$

Insulating materials, electrical, properties, measurement.......................... Interference........................... Intensity measurements, sound.............

Inverse fading of radio signals.............. Iridium. determination in platinum alloys....... 325 spectrographic examination of.......... 325

Iron ................................ 325 arc spectra......................... ${ }^{263}$

spectrum..................... 273 carbon alloys, thermal analysis of thermoelectric method of thermal analysis. separation from iridium.

\section{$\mathrm{J}$}

Jolliffe, C. B., and Miss J. A. Rodman, A quantitative study of regeneration by inductive feed back.......................

\section{K}

Karcher, J. C., A method for the measurement of sound intensity....................... Keivin, Burns, W. F. Meggers, C. C. Kiess and, Determination of secondary standards of wave length from the new international iron arc.............................. Kenyon, Frieda, Grace Hazen and, Primary radio-frequency standardization by use of the cathode-ray oscillograph. ..............

Kiess, C. C., Series in the arc spectrum of molybdenum.........................

- W. F. Meggers, Keivin Burns and, Determination of secondary standards of wave length from the new international iron arc.

Page 307 697 429 rometer measurements of the longer waves in the iron are spectrum...................... Kruse, S., J. H. Dellinger, L. E. Whittemore and, A study of radio signal fading......... 
$\mathbf{L}$

Lenses, monaxial aberrations.

Luminous efficiency of radiant energy ......

\section{M}

Magnetic, properties and mechanical stress..

Measurement of resistance................ properties electrical insulating materials.

Measurements of thermal dilatations.........

Mechanical properties, electrical insulating materials, measurement. ...............

Meggers, W. F., C. C. Kiess, and Keivin Burns, Determination of secondary standards of wave length from the new international iron arc.

ne. and C. Kiess, Interferometer meas..... ments of the longer waves in the iron arc spectrum.............................

Merritt, George E., Application of the interferometer to measurements of the thermal dilatation of ceramic materials.............

Meteorological conditions, effect on radio transmission.

Microstructure, molybdenum............... Mohler, F. L., Arthur E. Ruark, Paul D. Foote, R. L. Chenault, and, Spectra and critical potentials of fifth group elements...

Moisture absorption, electrical insulating naterials, measurements.

Molybdenite, thermoelectrical and actinoelectrical properties. ultra-violet reflecting power ............

Molybdenum, series in the arc spectrum of.. thermal expansion......................

Mutual inductance calculations............ of circular circuits. . . . . . . . . . . . . . of circular filaments............... of coaxial circles. .................... determinations...................

\section{$\mathbf{N}$}

Navigation, aerial, radio, aid to............ marine, radio, aid to.................

Nitrogen, spectral classifications............

Nocturnal variation of radio signals..........

\section{0}

Oscillograph, cathode-ray

\section{$\mathbf{P}$}

Palladium, effect on determination of iridium............................... Parabolic reflector for directive transmission. Parallel wire system.

Photographic lenses, aberrations............ Power loss, electrical insulating materials, measurement.

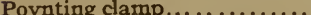

Preston, J. L., J. H. Dellinger and, Methods of measurement of properties of electrical insulating materials................... Primary radio-frequency standardization....

by use of the cathode-ray oscillograph.......................

standard wave meters................ wave meter standardization. ............ Progressive fading of radio signals .......... Pyrites, ultra-violet reflecting power........

\begin{tabular}{r|} 
Page \\
587 \\
297 \\
131
\end{tabular}

\section{$\mathbf{R}$}

Radiant energy, visibility of ..............

Radio................................ ${ }_{23}$

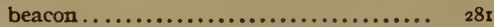

fading.......................... 193

frequency properties, insulating ma-

terials, measurement ................

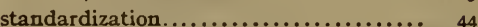

transmitting set..................... $28 \mathrm{r}$

Reception, radio, on airplanes............ 28I

Reflecting power, pyrites, stibnite, molybdenite, galena, graphite, duralumin.........

Reflection of radio waves..................

of very short electric waves..............

Refraction of radio waves..................

Regeneration...........................

Resistance, alternating-current, of solenoids. . measurements . ............... radio-frequency, measurement........... variation method, radio measurements..

Resistivity, insulating materials, measurement.............................

Rhodium, effect on determination of iridium. Rodman, Miss J. A., C. B. Jolliffe and, A quant itative study of regeneration by inductive feed back. ........................

Ruark, Arthur, F. L. Mohler, Paul D. Foote, and $R$. $L$. Chenault, Spectra and critical potentials of fifth group elements..........

Rythenium, effect on determination of

\section{$\mathbf{S}$}

Safety, method of improvement in aerial and marine navigation...................... Sanford, R. L., Effect of stress on the magnetic properties of steel wire.................. Screen, shielding, radio measurements....... Seasonal variation of radio signals . ..........

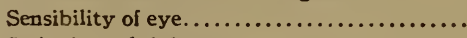
Series in molybdenum..................... Shielding, radio measuring circuits.......... Short-time intervals.................... Short-wave directive transmission........... Short waves, susceptibility of fading......... Signal, radio, effect of fading................. strength, variation of .....

Smith, Alva, Frank Wenner and, Measurement of low resistance by means of the Wheatstone bridge ..................... Snow, Chester, Spectroradiometric analysis of radio signals . . . . . . . . . . . . . . . . . . . .

Solenoids, alternating-current, resistance and inductance of ......................... Sound intensity measurements............. Sparks, C. Matilda, Harvey L. Curtis and, Formulas, tables, and curves for computing the mutual inductance of two coaxial circles............................. Specimens, electrical insulating materials, preparation......................... Spectra, spectral classifications, and excitation of spectra of arsenic, antimony, bismuth, and nitrogen......................

Spectrum analysis....................... visibility of radiant energy in...........
$28 \mathrm{x}$

$68 \mathrm{r}$

39

193

$13 \mathrm{x}$

II 3

39

I 7

I

I 93

193

I93

297 
Standard wave meter, Bureau of Standards.. $\quad \begin{array}{r}\text { Page } \\ 445\end{array}$

Standardization, radio-frequency ........... 445

Standards of wave length.............. 263, 273

Standing waves on wire ................ 487

Steel wire, effect of stress on magnetic prop-

erties...............................

Stibnite, ultra-violet reflecting power........

Strays, relation to radio reception............

Stress, effect on magnetic properties of steel wire.

Sunrise and sunset, effect on radio transmission.

Swinging, effect of reception of signals ........

\section{$\mathrm{T}$}

Tables for computing mutual inductance.... the calculation of inductance...........

Tensile strength, electrical insulating materials, measurement...................

Terra cottas, thermal expansivities of.........

Terrestrial magnetism, relation to radio signals.

Testing, electrical insulating materials.......

Thermal expansion, aluminum .............

aluminum alloys .................

electrical insulating materials, meas-

urement.

molybdenum.....................

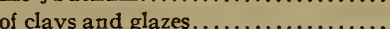

expansivities ........................

Time measurement of short-time intervals. .

Tuning fork, use as fundamental for radiofrequency standardization
I93

193

$54 \mathrm{I}$ $64 \mathrm{I}$ 39
Tyndall, E. P. T., K. S. Gibson and, Visibility of radiant energy..................

$\mathrm{U}$

Ultra-radio frequencies, determination of.... frequency directive transmission......... Ultra-violet refecting power, pyrites, stibnite, molybdenite, graphite, galena, duralumin

V

Page 131

487

Vegetation, effect on signal intensity........ 193

Verilite, thermal expansion............... 697

Visibility of radiant energy ............... I3I

Volume resistivity, measurement.......... 39

W

Wave length $\ldots \ldots \ldots \ldots \ldots \ldots \ldots \ldots \ldots, 263,273$

relation to fading ................. 193

meter standardization ................ 445

transmission phenomena............. 193

Waves, standing, on wires............... 487

Weather, effect on radio transmission........ $\quad$ I93

Wenner, Frank, and Alva Smith, Measurement of low resistance by means of the Wheatstone bridge................... 297

Wheatstone bridge ................... 297

Whittemore, L. E., J. H. Dellinger, S. Kruse, and, A study of radio signal fading....... 193

Wire, steel, effect of stress on magnetic properties............................ Wind drift indicator for aerial navigators.... $Z$

Zone, equisignal as an aid to navigation..... $28 \mathrm{I}$ 